\title{
Corrosion Inhibition of Some Organic Compounds on Low Carbon Steel in Hydrochloric Acid Solution
}

\author{
Omyma R. Khalifa and Shadia M. Abdallah* \\ Department of Chemistry, University College of Women for Arts, Science, and Education, Ain \\ Shams University, Asma Fahmy Street, Heliopolis-11341, Cairo, Egypt
}

Received 27 October 2010; accepted 20 January 2011

\begin{abstract}
The effect of N-[N`-(4-methoxyphenyl)benzenesulphonamido]-3-carboxy-4-methyl-4(4-methylphenyl)-3-butenamide 1, N-(N`-phenylbenzenesulphonamido)-3-carboxy-4methyl-4-(4-methylphenyl)-3-butenamide $\mathbf{2}$, and $\mathrm{N}$-[N'-(4-chlorophenyl)benzenesulphonamido]-3-carboxy-4-methyl-4-(4-methylphenyl)-3-butenamide 3, on the corrosion of low carbon steel in $1 \mathrm{M}$ hydrochloric acid solution has been studied by weight loss measurements and potentiodynamic technique over the temperature range $30-60{ }^{\circ} \mathrm{C}$. Results obtained showed that protection efficiency increased with the increase in concentration of the different organic compounds used and decreased with the increase in temperature. Langmuir adsorption isotherm at all temperatures was studied. The phenomenon of physical adsorption is proposed from the values of $E_{a}$ and $\Delta G_{\text {ads. }}^{\circ}$. Results obtained showed that compound $\mathbf{1}$ is the best inhibitor, and the protection efficiency follows the order: $\mathbf{1}>\mathbf{2}>\mathbf{3}$.
\end{abstract}

Keywords: corrosion, protection, steel, benzenesulphonamidobutenamide derivatives.

\section{Introduction}

Steel is the most important engineering and construction material in the world. It is used in every aspect of our lives (automotive manufactures, construction products, steel toecaps, protective footwear, refrigerators, washing machines, cargo ships and so on).

Oxidation occurs at anodic site and reduction occurs at cathodic site. In acidic medium, hydrogen evolution reaction predominates. Corrosion inhibitors reduce or prevent these reactions; they are adsorbed onto the metal surface and act by a

\footnotetext{
* Corresponding author. E-mail address: shadiamabdallah@yahoo.com
} 
forming barrier to oxygen and moisture, and some of the inhibitors facilitate the formation of a passive film on the metal surface.

Several works have studied the influence of organic compounds containing nitrogen on the corrosion of steel in acidic media [1-9]. Most organic inhibitors act by adsorption on the metal surfaces [4]. The effect of surfactants has been studied and it was shown that the protection efficiency increases with the number of carbon atoms in the molecule [4]. Thermodynamic model is an important tool to study the mechanism of the inhibitor on the corrosion of metal. A thermodynamic model for the adsorption process has been suggested [10-11].

In the present work, the protection effect of three compounds (1, 2, and 3) on low carbon steel surface in aggressive $1 \mathrm{M} \mathrm{HCl}$ solution is presented.

\section{Experimental}

Low carbon steel used in this study has the following composition (wt \%): $\mathrm{C}$ (0.26), Si (0.08), Mn (0.6), S (0.006), P (0.008) and the remainder is iron. All specimens were mechanically polished with a sequence of emery papers of various grades (150, 320 and 600) and thoroughly washed with bidistilled water and acetone. Dried and cleaned specimens were kept in a desiccator over silica gel. The concentration of the blank corrodent, $\mathrm{HCl}$ (BDH chemical supplies laboratory, England) prepared and used was $1 \mathrm{M}$.

The investigation of inhibiting properties of $\mathrm{N}-\left[\mathrm{N}^{`}-(4-\right.$ methoxyphenyl) benzenesulphonamido]-3-carboxy-4-methyl-4-(4-methylphenyl)-3-butenamid $\mathbf{1}$, $\mathrm{N}$-(N`-phenylbenzenesulphonamido)-3-carboxy-4-methyl-4-(4-methylphenyl)-3butenamide 2 , and $\mathrm{N}$-[N`-(4- chlorophenyl)benzenesulphonamido]-3-carboxy-4methyl-4-(4-methylphenyl)-3-butenamide 3, which have been prepared from the condensation of 2-[methyl(4-methylphenyl)methylene]butanedioic anhydride [12] with different $\mathrm{N}$-substituted 4-aminobenzenesulfonamide derivatives [13] under both conventional thermal heating and microwave irradiation techniques, has been performed using the weight loss method and electrochemical studies (potentiodynamic polarization techniques).

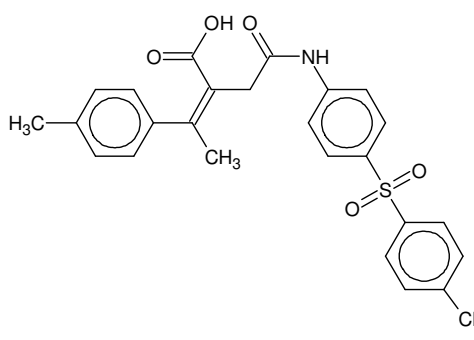

Compound 1

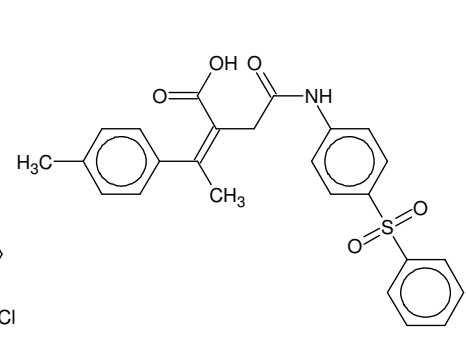

Compound 2

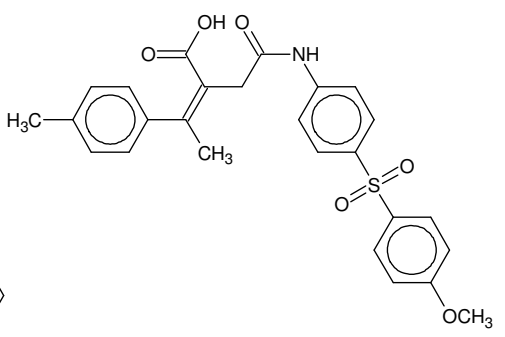

Compound $\mathbf{3}$

In the weight loss method, the progress of the corrosion reaction was calculated by determining the weight loss of the coupons (obtained as the differences in the weight of the coupons after immersion in different solutions of the system and their original weight). 
The weight loss measurements were carried out at 30, 40, 50 and $60{ }^{\circ} \mathrm{C}$ using sheets of the substrates with dimensions $2 \times 2.5 \mathrm{~cm}$. The sheets were suspended in $20 \mathrm{~mL}$ solution of $1 \mathrm{M} \mathrm{HCl}$ with and without the different inhibitor concentrations (50-400 ppm) for 1 hour. The loss in weight per area $\left(A=10 \mathrm{~cm}^{2}\right)$ in $\mathrm{mg} / \mathrm{cm}^{2}\left(\mathrm{~W}_{\mathrm{t}}\right)$, the corrosion rate $\left(\mathrm{R}_{\mathrm{corr}}\right)$, and the percentage of protection efficiency (percent protection), were calculated over different inhibitor concentrations according to the following equations:

$$
\begin{gathered}
\mathrm{W}_{\mathrm{t}}=\frac{\mathrm{W}_{\mathrm{o}}-\mathrm{W}_{1}}{\mathrm{~A}} \\
\mathrm{R}_{\text {corr }}=\frac{\mathrm{W}_{\mathrm{t}}}{\mathrm{t}} \\
\mathrm{P} \%=\left[1-\left(\frac{R_{\text {corr }}^{\prime}}{R_{\text {corr }}}\right)\right] \times 100
\end{gathered}
$$

where $\mathrm{W}_{\mathrm{o}}$ is the original weight $(\mathrm{mg})$ and $\mathrm{W}_{1}$ the weight after immersion in the test electrolyte, $\mathrm{t}$ the immersion time (hour), and $\mathrm{R}_{\text {corr }}$ and $\mathrm{R}_{\text {corr }}$ are the corrosion rates with and without an inhibitor, respectively.

Two measurements were performed in each case and the mean value of the weight loss was reported.

Potentiodynamic polarization studies were carried out with the test specimens having an exposed area of $1 \mathrm{~cm}^{2}$ using an EG\&G PARC model 350A (console) in the range from $-250 \mathrm{mV}$ to $1000 \mathrm{mV}$, using a scan rate of $0.5 \mathrm{mV} / \mathrm{sec}$. The cell consisted of test specimens as working electrode and a saturated calomel electrode (SCE) as reference electrode. Two carbon electrodes were used as counter electrodes.

\section{Results and Discussion}

\section{Corrosion rate and protection efficiency}

Fig. 1 shows the average corrosion rate $\left(\mathrm{R}_{\text {corr }}\right)$ of low carbon steel, expressed as mg hour ${ }^{-1} \mathrm{~cm}^{-2}$, as a function of the logarithmic concentration of compounds $\mathbf{1}, \mathbf{2}$ and 3 in $1 \mathrm{M} \mathrm{HCl}$ solutions at $30^{\circ} \mathrm{C}$. It demonstrates that the addition of the organic inhibitors decreases the corrosiveness of the acid. The corrosion rate of low carbon steel depends on the concentration of inhibitors. Their actions depend on the nature of substituent.

\begin{tabular}{|c|c|c|c|c|}
\hline Comp. & $\overline{\mathbf{E}_{\mathrm{a}}}$ & $\Delta \mathbf{H}\left(\mathrm{kJ} \mathrm{mol}^{-1}\right)$ & $-\Delta \mathbf{G}\left(\mathrm{kJ} \mathrm{mol}^{-1}\right)$ & $-\Delta \mathbf{S}\left(\mathbf{J ~ m o l}^{-1} \mathbf{K}^{-1}\right)$ \\
\hline 1 & 57.7 & 53.54 & 30.07 & 278 \\
\hline 2 & 53.4 & 51.45 & 29.18 & 266 \\
\hline 3 & 43.9 & 47.7 & 28.34 & 251 \\
\hline Pure & 38.3 & 38.18 & - & - \\
\hline
\end{tabular}

Table 1. Thermodynamic activation parameters of the dissolution of low carbon steel in $1 \mathrm{M} \mathrm{HCl}$ in the presence of $400 \mathrm{ppm}$ of different additives. 


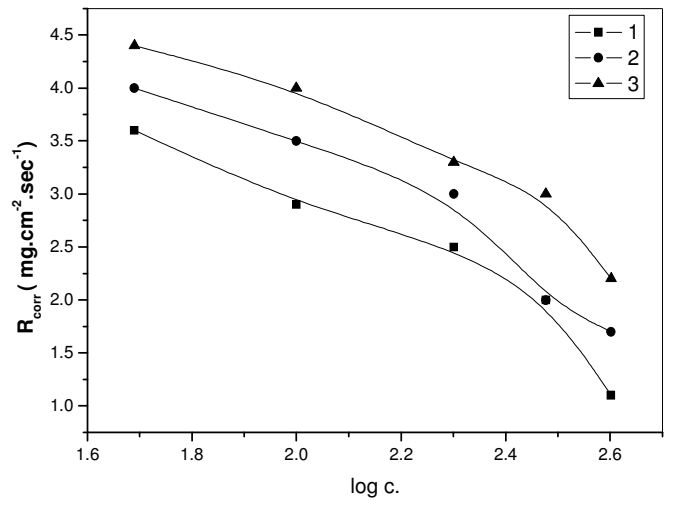

Figure 1. Corrosion rate of low carbon steel in $1 \mathrm{M} \mathrm{HCl}$ solution in presence of different concentrations of compounds $\mathbf{1}, \mathbf{2}$ and $\mathbf{3}$.

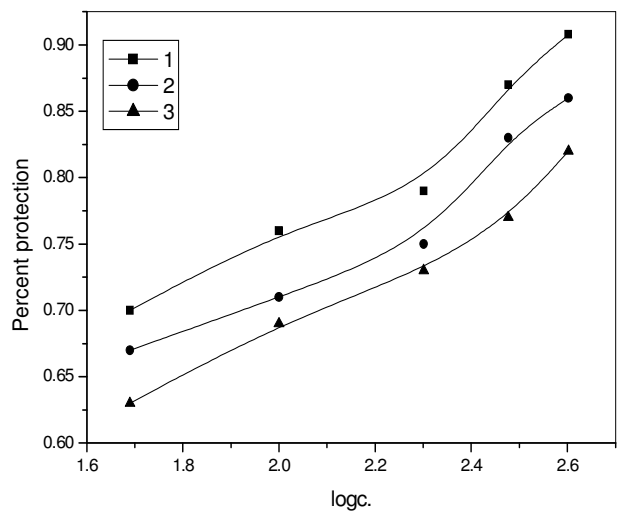

Figure 2. Protection efficiency of low carbon steel in $1 \mathrm{M} \mathrm{HCl}$ solution in presence of different concentrations of compounds $\mathbf{1 , 2}$ and $\mathbf{3}$ at $30^{\circ} \mathrm{C}$.

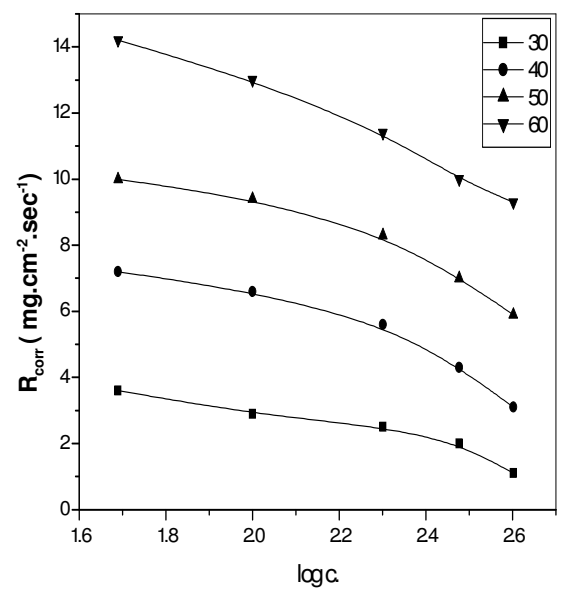

Figure 3. Corrosion rate of low carbon steel in $1 \mathrm{M} \mathrm{HCl}$ solution in the presence of different concentrations of compound 1 , at different temperatures. 
Fig. 2 shows the variation of the protection efficiency of low carbon steel as a function of the logarithmic concentration of compounds $\mathbf{1}, 2$ and $\mathbf{3}$ in $1 \mathrm{M} \mathrm{HCl}$ solution at $30{ }^{\circ} \mathrm{C}$. The protection efficiency increases with increasing the inhibitor concentrations. Also, the protection efficiency increases from compound $\mathbf{1}$ to compound $\mathbf{2}$ to compound $\mathbf{3}$, as shown in Table 1.

Fig. 3 shows the variation of the corrosion rate of low carbon steel, as a function of the logarithmic concentrations of compound $\mathbf{1}$ at different temperatures.

Fig. 4 shows the effect of the concentration of compound $\mathbf{1}$ on the protection efficiency of low carbon steel, at various temperatures. The same behavior is observed for compounds $\mathbf{2}$ and $\mathbf{3}$.

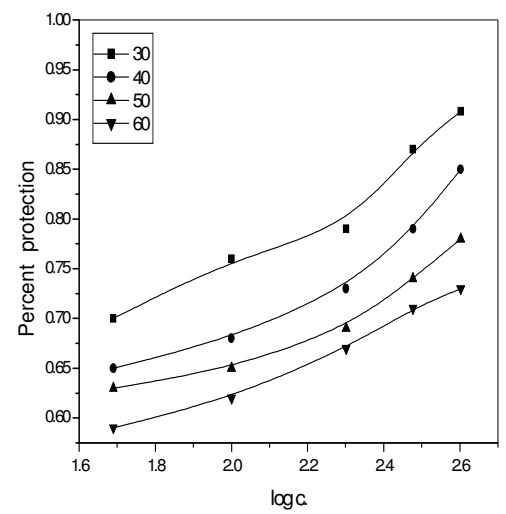

Figure 4. Protection efficiency of low carbon steel in $1 \mathrm{M} \mathrm{HCl}$ solution in presence of different concentrations of substance 1 at different temperatures.

In general, the protection efficiency increases with decreasing temperature. This indicates that the adsorption of these compounds on low carbon steel surfaces is a physical adsorption.

\section{Adsorption isotherm}

It has been reported that the adsorption of an organic compound onto the surface of the metal is dependent on the physicochemical properties of the inhibitor molecules such as steric factors, functional groups, electron density (i.e. charge distribution) at the donor atoms and л orbital character of donating electrons and also on the nature of the substrating metal and the type of interaction between organic molecules and the metallic surface [14].

In order to obtain a better understanding of the electrochemical process on the metal surface, adsorption isotherms at $30{ }^{\circ} \mathrm{C}$ were drawn. The degree of surface coverage $(\theta)$ at different concentrations of each inhibitor in acidic medium has been evaluated from the weight loss measurements, according to equation (4):

$$
\theta=\left[1-\left(\frac{R_{c o r r}^{\prime}}{R_{c o r r}}\right)\right]
$$

Data related to the degree of the surface coverage $(\theta)$ were tested graphically in order to determine the most suitable adsorption isotherm. 


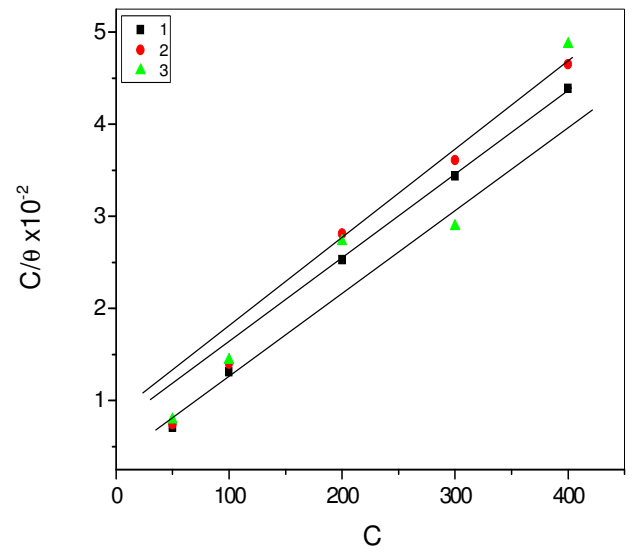

Figure 5. Langmuir's adsorption isotherm of compounds 1, 2 and 3 on the surface of low carbon steel in $1 \mathrm{M} \mathrm{HCl}$ at $30^{\circ} \mathrm{C}$.

As shown in Fig. 5, the plot of $\mathrm{C} / \theta$ versus $\mathrm{C}$ for low carbon steel in $1 \mathrm{M} \mathrm{HCl}$ with different inhibitor concentrations, yields a straight line showing that the adsorption of these inhibitors is well described by the Langmuir isotherm. These isotherms are described by equation (5),

$$
\begin{gathered}
\frac{C}{\theta}=\frac{1}{k}+C \\
k=\frac{1}{55.5} \exp \left(\frac{-\Delta G^{\circ}}{R T}\right)
\end{gathered}
$$

where $C$ is the inhibitor concentration, $k$ the adsorption constant, and $\Delta G^{\circ}$ the standard free energy of adsorption.

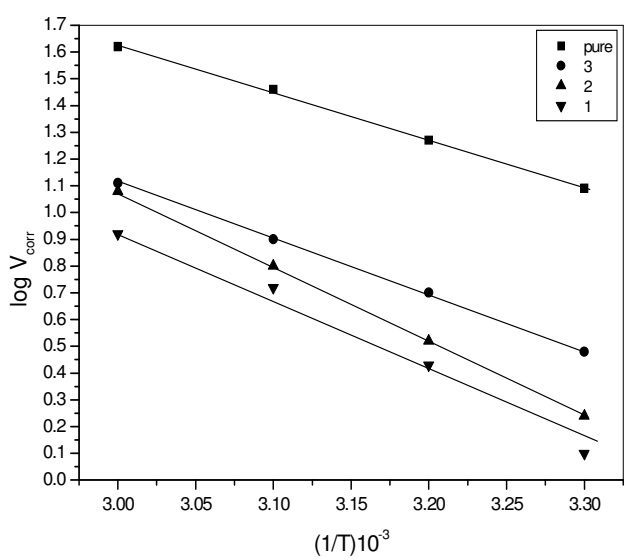

Figure 6. Arrhenius plot of low carbon steel in $1 \mathrm{M} \mathrm{HCl}$ with and without compounds 1,2 and 3.

The calculated values of $\mathrm{k}$ and $\Delta \mathrm{G}^{\circ}$ of the adsorption reaction of low carbon steel are shown in Table 1. The negative value of the standard free energy of 
adsorption indicates spontaneous adsorption of these inhibitors on low carbon steel. This means that the inhibitive action of these substances results from the physical adsorption [15], as mentioned before.

\section{Activation energy}

According to the Arrhenius equation,

$$
\ln k=\ln A+\frac{-E_{a}}{R T}
$$

where $E_{a}$ is the apparent activation energy, $A$ is the pre-exponential parameter of Arrhenius, and $\mathrm{k}$ is the rate of a metal dissolution reaction, and is directly related to the corrosion rate by equation (8):

$$
\ln R_{\text {cor }}=\ln A+\frac{-E a}{R T}
$$

Fig. 6 shows the logarithmic plot of the corrosion rate of low carbon steel in $1 \mathrm{M}$ $\mathrm{HCl}$ as a function of $(1 / \mathrm{T})$ in free and inhibited solutions, respectively. For the inhibitor free solution, the energy of activation, evaluated from these graphs, is found to be equal to $38.18 \mathrm{~kJ} \mathrm{~mol}^{-1}$ for low carbon steel. This value is in agreement with the literature data [16]. In the presence of anyone of the studied inhibitors, the energy of activation increases. For a $400 \mathrm{ppm}$ concentration of compounds 1, $\mathbf{2}$ and $\mathbf{3}$, the calculated values of the apparent activation energies are $57.7,53.4$ and $43.9 \mathrm{~kJ} / \mathrm{mol}$ for low carbon steel. This indicates that the formation of the adsorption film occurs by a physical mechanism [17].

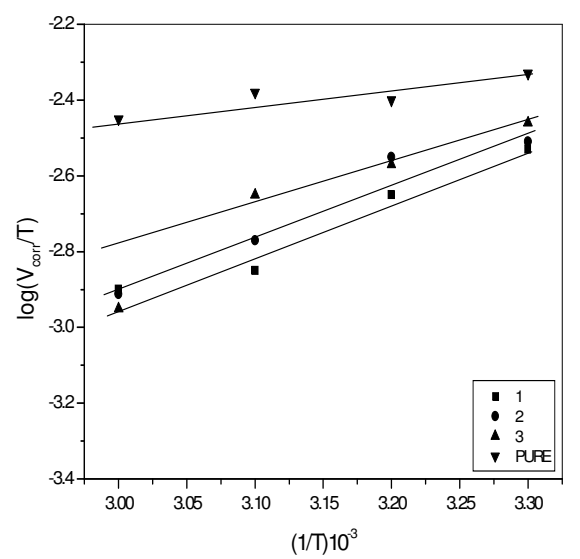

Figure 7. $\log \left(\mathrm{V}_{\text {corr }} / \mathrm{T}\right)$ vs. $(1 / \mathrm{T})$ of low carbon steel in $1 \mathrm{M} \mathrm{HCl}$ in absence and presence of compounds $\mathbf{1}, \mathbf{2}$ and $\mathbf{3}$.

Enthalpy and entropy of activation, $\Delta \mathrm{H}^{\circ}$ and $\Delta \mathrm{S}^{\circ}$, were obtained by applying the transition state equation (9):

$$
V_{\text {corr }}=\frac{R}{N H} \exp \left(\frac{\Delta S^{0}}{R}\right) \exp \left(\frac{-\Delta H^{0}}{R T}\right)
$$


By plotting $\log \left(\mathrm{R}_{\text {corr }} / \mathrm{T}\right)$ vs. $(1 / \mathrm{T})$ at $400 \mathrm{ppm}$ of the tested inhibitors, straight lines are obtained for low carbon steel, as shown in Fig. 7. The values of $\Delta \mathrm{H}^{\circ}$ and $\Delta \mathrm{S}^{\circ}$ can be calculated from the slopes and intercepts of the straight lines, respectively, Table 1 .

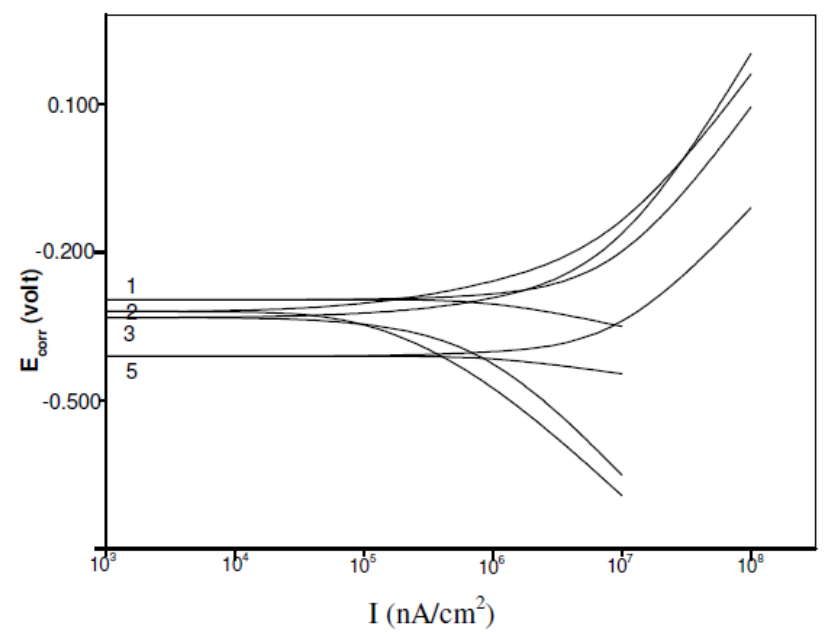

Figure 8. Potentiodynamic polarisation curves of low carbon steel in $1 \mathrm{M}$ HClwith different concentrations of compound 1 .

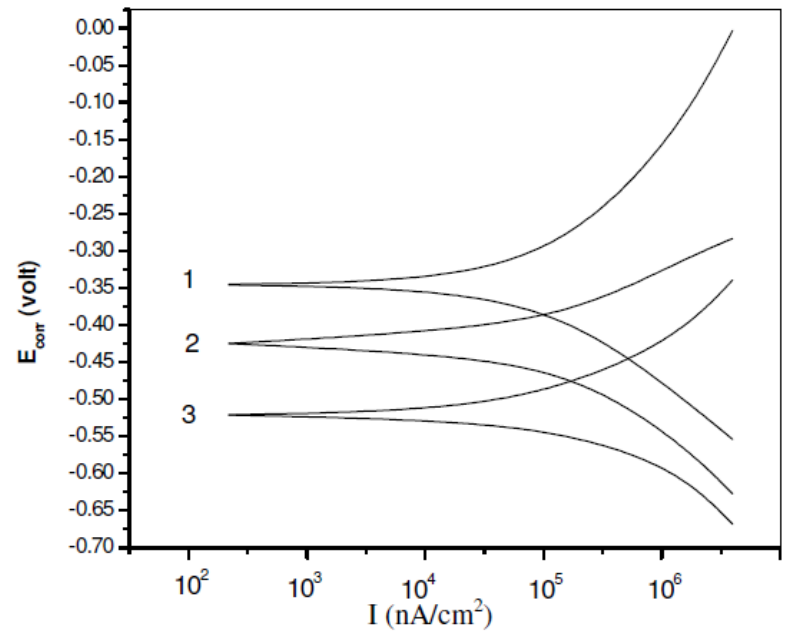

Figure 9. Potentiodynamic polarisation curves of low carbon steel in $1 \mathrm{M} \mathrm{HCl}$ in absence and presence of the tested inhibitors.

The results showed that the enthalpy of activation is positive. The positive sign of the enthalpy reflects the endothermic nature of the low carbon steel dissolution process [18].

Fig. 8 and 9 show potentiodynamic polarization curves and show that as the concentration of the tested compounds increased, the protection efficiency increases (e.g., compound 1 in Fig. 8). Also Fig. 9 shows that the protection efficiency of the tested compounds follows the compounds sequence $\mathbf{1}>\mathbf{2}>\mathbf{3}$.

\section{Chemical structure and corrosion inhibition of low carbon steel}

Inhibition of corrosion of low carbon steel in hydrochloric acid by the prepared compounds 1-3 as determined by weight loss, potentiodynamic polarization and 
thermodynamic measurements was found to depend on the concentration and structure of the inhibitor. The decrease in the corrosion rate in the presence of inhibitor with the increase in concentration of the inhibitor was indicated by the shift of Tafel lines to more negative potential regions and the temperature indicated that the corrosion inhibition takes place by adsorption of the inhibitors at the electrode solution interface [15].

Protection efficiency was found to depend on the number of adsorption active centers in the molecule and their charge density. Adsorbed molecules on the surface of the corroding metal interfere with cathodic and/or anodic reaction. Inhibition of these reactions would depend on the degree of surface coverage of the metal with the adsorbate. Competitive adsorption is assumed to occur on the surface of the metal between the aggressive chloride ions on one hand and the inhibitor molecule on the other. The order of decreasing protection efficiency of the tested compounds is compound $\mathbf{1}>\mathbf{2}>\mathbf{3}$.

All compounds used have high molecular weight; compound $\mathbf{1}$ is the superior among the investigated compounds. This can be attributed to the presence of mesomeric effect exerted by the methoxy group which increases the electron donating ability to the vacant d-orbital of the metal. On the other hand, compound $\mathbf{2}$ is more efficient than compound $\mathbf{3}$. This can be attributed to the presence of electron attracting chlorine atom in compound $\mathbf{3}$, which decreases the electron donating ability to the vacant d-orbital of the metal by its inductive effect (-I). This also decreases the delocalization of the $\pi$-electron on the aromatic ring resulting from the decrease of electron density on the aromatic ring.

\section{Conclusion}

Results show that all the three compounds used N-[N-(4methoxyphenyl)benzenesulphonamido]-3-carboxy-4-methyl-4-(4-methyl-

phenyl)-3-butenamide $\mathbf{1}, \quad \mathrm{N}$-( $\mathrm{N}^{`}$-phenylbenzenesulphonamido)-3-carboxy-4methyl-4-(4-methylphenyl)-3-butenamide 2 and $\mathrm{N}$-[N'-(4-chlorophenyl) benzenesulphonamido]-3-carboxy-4-methyl-4-(4-methylphenyl)-3-butena-mide

3 , have great protection of low carbon steel in $1 \mathrm{M} \mathrm{HCl}$.

The increase in temperature increases corrosion rate but decreases the protection efficiency.

Protection efficiency was found to increase with increasing the concentration of compounds 1, 2 and $\mathbf{3}$.

The adsorption of compounds $\mathbf{1}, \mathbf{2}$ and $\mathbf{3}$ on low carbon steel obeys Langmuir adsorption isotherm.

\section{References}

1. M.K. Chatterjee, K.P. Benerjee, Mukherjee, Ind. J. Technol. 29 (1991) 191199.

2. M. Elachouri, M.S. Hajji, S. Kertit, E.M. Essassi, M. Salem, R. Coudert, Corros. Sci. 37 (1995) 381-389. 10.1016/0010-938X(94)00134-R 
3. B. Mernari, H. Elattari, M. Taisnel, F. Bentiss, M. larenee, Corros. Sci. 40 (1998) 391-401. 10.1016/0010-938X(94)00134-R

4. F. Bentiss, M. Traisnel, M. Lagenee, Corros. Sci. 42 (2000) 127-134. 10.1016/S0010-938X(99)00049-9

5. L. Elkadi, B. Mernari, M. Traisnel, F. Bentiss, M. Lagrenee, Corros. Sci. 42 (2000) 703-710. 10.1016/S0010-938X(99)00101-8

6. A. Elkanouni, S. Kerrtit, A. Srhiri, A. B. Bachir, Bull. Electrochem. 12 (1996) 517-525.

7. R. Walker, Corrosion 31 (1975) 97-102.

8. S. Kertit, B. Hammouti, Appl. Surf. Sci.93 (1996) 59-66. 10.1016/01694332(95)00189-1.

9. F. Bentiss, M. Lagrenee, M. Traisnel, J.C. Hornez, Corros. Sci. 41 (1999) 789-795. 10.1016/S0010-938X(98)00153-X

10. E. Khamis, Corrosion 46 (1990) 476-484.

11. T.P. Zhao, G.N. Mu, Corros. Sci. 41 (1999) 1937-1945. 10.1016/S0010938X(99)00029-3

12. S. El-Wahhab, L. El-Assal, S. Abd-Elaziz, Egypt J. Chem. 11 (1968) 293298.

13. A.I. Vogel, "Practical Organic Chemistry", fourth edition, (1976) 65-68.

14. M. Bouklah, N. Benchat, B. Hammouti, A. Aouniti, S. Kertit, Mater. Lett. 60 (2006) 1901-1907. 10.1016/j.matlet.2005.12.051

15. H.B. Rudresh, S.M. Mayanna, Surf. Technol. 6 (1977) 139-146. 10.1016/0376-4583(77)90004-8

16. E.A. Noor, Corros. Sci. 47 (2005) 33-39. 10.1016/j.corsci.2004.05.026

17. G. K. Gomma, M. H. Wahdan, Mater. Chem. Phys. 39 (1995) 209-213. 10.1016/0254-0584(94)01436-K

18. G. Quartarone, G. Moretti, A. Tassan, A. Zingales, Werkst. Korrosion 45 (1994) 641-652. 10.1002/maco.19940451203 